\title{
Comparison of different methods for the in situ measurement of forest litter moisture content
}

\author{
C. Schunk ${ }^{1}$, B. Ruth ${ }^{2, *}$, M. Leuchner ${ }^{1,3, a}$, C. Wastl ${ }^{1, b}$, and A. Menzel ${ }^{1,3}$ \\ ${ }^{1}$ Ecoclimatology, Technische Universität München, Hans-Carl-von-Carlowitz-Platz 2, 85354 Freising, Germany \\ ${ }^{2}$ Institute of Soil Ecology, Helmholtz Zentrum München - German Research Center for Environmental Health, \\ Ingolstädter Landstraße 1, 85764 Neuherberg, Germany \\ ${ }^{3}$ Institute for Advanced Study, Technische Universität München, Lichtenbergstraße 2a, 85748 Garching, Germany \\ ${ }^{a}$ now at: Springer Science + Business Media B.V., Dordrecht, the Netherlands \\ b now at: Central Institute for Meteorology and Geodynamics, Vienna, Austria \\ * retired \\ Correspondence to: C. Schunk (schunk@wzw.tum.de)
}

Received: 23 March 2015 - Published in Nat. Hazards Earth Syst. Sci. Discuss.: 10 June 2015

Revised: 18 January 2016 - Accepted: 22 January 2016 - Published: 9 February 2016

\begin{abstract}
Dead fine fuel (e.g., litter) moisture content is an important parameter for both forest fire and ecological applications as it is related to ignitability, fire behavior and soil respiration. Real-time availability of this value would thus be a great benefit to fire risk management and prevention. However, the comprehensive literature review in this paper shows that there is no easy-to-use method for automated measurements available. This study investigates the applicability of four different sensor types (permittivity and electrical resistance measuring principles) for this measurement. Comparisons were made to manual gravimetric reference measurements carried out almost daily for one fire season and overall agreement was good (highly significant correlations with $0.792<=r<=0.947, p<0.001)$. Standard deviations within sensor types were linearly correlated to daily sensor mean values; however, above a certain threshold they became irregular, which may be linked to exceedance of the working ranges. Thus, measurements with irregular standard deviations were considered unusable and relationships between gravimetric and automatic measurements of all individual sensors were compared only for useable periods. A large drift in these relationships became obvious from drought to drought period. This drift may be related to installation effects or settling and decomposition of the litter layer throughout the fire season. Because of the drift and the in situ calibration necessary, it cannot be recommended to use
\end{abstract}

the methods presented here for monitoring purposes and thus operational hazard management. However, they may be interesting for scientific studies when some manual fuel moisture measurements are made anyway. Additionally, a number of potential methodological improvements are suggested.

\section{Introduction}

\subsection{Background}

Dead fine fuel moisture content has been a focus of forest fire research since its start, mainly because it is one of the critical determinants of ignitability and fire behavior (Pyne et al., 1996). A range of applications such as planning of prescribed fires, diurnal fire danger rating (i.e., hazard management in general), and model validation require knowledge of the in situ fine fuel moisture dynamics. However, fine fuel moisture dynamics are not easily measured since standard techniques, e.g., destructive sampling and oven drying, onsite moisture analysis of destructive samples (e.g., Wiltronics ME2000, Campbell Scientific DMM600) or the weighing of fuel moisture sticks, are very cumbersome and labor intensive. Results of these measurements often become available only after a remarkable delay (e.g., drying time) and are therefore not suitable for real-time decision making, espe- 
cially as diurnal variations in fine fuel moisture can be of considerable importance.

Measuring fuel moisture content automatically is difficult because of a range of fuel properties: dead fine fuels such as litter layers are often highly heterogeneous and discontinuous with usually only a shallow depth as well as a low density and compactness (Chandler et al., 1983; Ferguson et al., 2002). Additionally, in temperate regions and deciduous stands, strong annual dynamics with a fresh supply of litter every fall followed by weathering and degradation throughout the rest of the year are present. Fuel moisture values can be expected to have a wide range from several $100 \%$ gravimetric fuel moisture content during or after rain to few $\%$ in dry periods. In this range, values less than $30 \%$ are of special importance for forest fire applications as they correspond to a high flammability (Wright, 1967).

\subsection{Existing and potential measurement techniques}

\subsubsection{Gravimetry}

The (non-automated) gravimetric method can be considered the standard technique for determining fuel moisture content. In many studies (e.g., Beck and Armitage, 2001; Wotton et al., 2005; Gonçalves et al., 2006; Lopes et al., 2006; Aguado et al., 2007), destructive manual sampling was used. The gravimetric moisture content $u_{\mathrm{G}}$ in $\%$ is determined from the sample wet $\left(m_{\mathrm{w}}\right)$ and dry $\left(m_{\mathrm{d}}\right)$ mass using

$u_{\mathrm{G}}=\frac{m_{\mathrm{w}}-m_{\mathrm{d}}}{m_{\mathrm{d}}} \times 100$.

Fuel drying is usually performed in drying ovens with temperatures ranging between 60 and $105^{\circ} \mathrm{C}$ and drying times of 24 to $48 \mathrm{~h}$, depending on the study considered. In a recent laboratory study, Matthews (2010) found that drying temperature has a significant effect on the oven-dry mass, and thus the fuel moisture content, and recommended $105^{\circ} \mathrm{C}$ for general use.

Time series can be created by repeating the destructive sampling process; however, the material sampled will be different at each time point. In the case of day-to-day time series, sampling has to be carried out at the same time every day to correctly account for the diurnal variation. Transport to the laboratory and drying time determine the delay until the moisture values become available. However, since gravimetric measurements offer the most direct and exact inference of fuel moisture, they are regarded as a reference method.

To facilitate measurements based on the identical fine fuel material, some researchers (e.g., Wright, 1967) used trays with fine fuel material which were periodically re-weighed in the field. The dry mass of those samples was determined before or after the field campaign. However, the modification of contact to deeper layers (e.g., duff, soil) as well as loss, degradation or accumulation of material over time can cause errors in this method.
To create a truly automated measuring method, Wittich (2005) placed such a fine fuel tray on top of an automatically recording balance, thus constructing a "minilysimeter". Excess rainwater was allowed to run off freely through a fine-mesh wire netting. In addition to the drawbacks mentioned earlier, the influence of the underlying soil in natural conditions is therefore neglected and wind effects may produce additional errors. The operation of a system with moving parts may also be problematic in the field.

In other studies, the original fuels were replaced by other reference material such as fuel moisture sticks (Gisborne, 1933), which were also weighed periodically. In this case, attention has to be paid to the type of material (e.g., wood species) used and to weathering in order to obtain consistent results (Haines and Frost, 1978; Hardy and Hardy, 2007). The CS506 10-hour fuel moisture stick by Campbell Scientific, Inc., which uses time-domain reflectometry (TDR) to determine the moisture content of a 1.27 (diameter) by $50.8 \mathrm{~cm}$ (length) Pinus ponderosa (Dougl. ex Laws.) dowel, provides an automated version of this method.

\subsubsection{Near-fuel relative humidity}

Another technique for measuring fuel moisture content is to determine the relative humidity close to or inside (in case of porous fuel beds) fuels and to use specific field calibrations or equilibrium moisture content (EMC) curves determined in the laboratory for conversion. EMC is the moisture of a fuel in steady-state conditions, i.e., when it is subjected to constant climate conditions for an infinite time and there is no net moisture exchange (Pyne et al., 1996). Assuming instant fuel drying, EMC curves may be used for the conversion from near-fuel temperature and relative humidity for very light fuels. The duff hygrometer (Beall, 1928) for example used a rattan strip to measure relative humidity by its elongation; the instrument had a dial that could be calibrated to display fuel moisture content directly. In the building physics context, a similar application was the determination of moisture dynamics in a loose-fill wall insulation layer in Germany (Vogel et al., 2002), where the insulating material consisted of compacted wood chips. Since these particles have a similar moisture behavior as dead fine fuels in the forest, there is some comparability. In this case, the actual measurements were performed by a standard electronic relative humidity sensor buried in the center of the insulation layer. However, moisture contents exceeding fiber saturation (when external water is present) cannot be accounted for with this method. In forest fuels, this limit is at about $50 \%$ moisture content (Wright, 1967). Consistent sensor placement (cf. the general fuel properties mentioned above) and calibration are further challenges and led to the dismissal of the historical duff hygrometer (Hardy and Hardy, 2007). Conedera et al. (2012) used a temperature/relative humidity sensor in the "litter sentry" of their "FireLess2" system, which is inferring litter moisture from those parameters. However, the correla- 
tions between the FireLess 2 measurements and the manually determined volumetric litter moisture were poor, and high uncertainties in the critical low moisture range have been determined (Conedera et al., 2012).

\subsubsection{Electrical resistance}

The electrical resistance method is based on increased electrical resistance $(R)$ as a hygroscopic material becomes dryer. It is used mostly for determining construction timber moisture and works in the range of approximately 15-80\% moisture content, depending on the instrument used and material measured. Calibration equations exist but are mostly kept confidential by device manufacturers. One such equation can be found in Keylwerth and Noack (1956):

$\log _{10}\left[\log _{10}(R)\right]=u_{\mathrm{R}} \times a+b$,

where $u_{\mathrm{R}}$ is the moisture content as measured by the resistance method, $a$ and $b$ are constants characterizing the calibration equation and $\log _{10}$ is the logarithm to base 10. Early fire researchers tried to measure the moisture content and drying behavior of large logs with this technique (Hardy and Hardy, 2007). Fire danger rating based on the electrical resistance of manually removed bulk litter samples was tested by Schröder (1968), and a commercial product for moisture determination of such samples is the Wiltronics T-H fine fuel moisture meter (Chatto and Tolhurst, 1997). Borken et al. (2003) used the method to examine litter moisture automatically, measuring the electrical resistance of a $1.59 \mathrm{~mm}$ thick $9 \mathrm{~cm}^{2}$ basswood (Tilia americana L.) veneer which was placed within the litter. Apart from the limited measuring range both for very wet and very dry conditions, selection and ageing of the material measured as well as placement in the fuel bed (when trying to obtain in situ measurements) can be an issue. Because of the measuring principle, errors due to electrical interference or short circuit (at locally high moisture contents) can not be excluded. Reference materials different from the material under analysis (e.g., wood used in Borken et al., 2003) may show a distinctly different moisture behavior than the original fuels.

\subsubsection{Permittivity}

A variety of non-conductive materials in an electric field, e.g., between electrically charged, isolated sensor electrodes, reduce the aforementioned field and thus allow further electrical charge to flow onto the electrodes. The quantity of this effect, which especially occurs for water and humid materials, is scaled by the relative permittivity $\varepsilon$, ranging from 3 to 8 for dry soil (Thomas, 1966) to 80 for water. In the field, the sensor acts as a capacitor in an electrical oscillating circuit. With increasing water content, the permittivity is increased and thus the frequency of the oscillator reduced, providing an excellent measure of the material permittivity and thus the volumetric water content $\left(\theta,\left[\mathrm{cm}^{3} \mathrm{~cm}^{-3}\right]\right)$. Due to this way of measurement, the sensors are termed frequency domain (FD) sensors (Robinson and Dean, 1993; Nadler and Lapid, 1996). In contrast to that, fast voltage steps are reflected at the tips of the sensor rods in so-called TDR sensors (Topp et al., 1982; Campbell, 1990). TDR is the standard method; however, FD sensors employ a simpler and more direct measuring method (Lin, 2003), are less expensive and thus are more flexible in application. For a wide range of applications, TDR and FD results can be considered similar (v. Wilpert et al., 1998; Lin, 2003; Seyfried and Murdock, 2004). The calibration function depends on the measuring principle, sensor design and soil specifications. More recently, novel time domain transmission sensors have become available that are said to provide a performance similar to the TDR method at a reduced cost (Blonquist et al., 2005).

These measurement methods can also be used for materials other than soil, as long as the relative permittivity of the dry material is significantly different from that of water. In most materials the permittivity is dependent on the bulk density. However, changes in bulk density and the influence of temperature have been neglected in most cases.

The volumetric water content $(\theta)$ of a given material is calculated using

$\theta=\frac{m_{\mathrm{w}}-m_{\mathrm{d}}}{m_{\mathrm{d}}} \times \frac{\rho_{\mathrm{m}}}{\rho_{\mathrm{w}}}=u_{\mathrm{G}} \times \frac{\rho_{\mathrm{m}}}{\rho_{\mathrm{w}}}$,

where $\rho_{\mathrm{m}}$ and $\rho_{\mathrm{w}}$ are the bulk density of the measured material and the density of water, respectively, and $m_{\mathrm{w}}, m_{\mathrm{d}}$ as well as $u_{\mathrm{G}}$ correspond to the same parameters as in Eq. (1). With the knowledge of the mean bulk density, reference measurements can also be carried out on a gravimetric basis, facilitating much easier sampling and analysis. However, in practice the bulk density of soil or litter is frequently not constant (cf. soil settlement, annual changes in deciduous litter as described above), which causes problems that will be discussed in Sect. 4 of this paper.

Since the relative permittivity of forest litter (cf. the relative permittivity for oven-dry solid wood, which is 2 to 5 at room temperature; Forest Products Laboratory, 1999) is much lower than that of water, permittivity methods can also be used to measure directly the fine fuel moisture content. Additional difficulties of measuring dead fine fuels with this method are related to the fine fuel layer properties themselves. Especially their common shallowness, low-density and high porosity lead to problems in sensor installation and contact between the sensor and the measured material (Ferguson et al., 2002). Nevertheless, in an experimental burn study, Ruthford and Ferguson (2001) and Ferguson et al. (2002) tried this approach using in situ field calibration. Over a whole season, eight TDR sensors (CS-615 two-rod sensors with a length of $30 \mathrm{~cm}$ and a separation of $3.2 \mathrm{~cm}$ by Campbell Scientific, Inc.) were installed in the litter and duff layers as well as in the underlying sand of a longleaf pine (Pinus palustris Mill.) forest in Florida. Individual reference measurements were made by (almost) weekly volu- 
metric sampling for litter and duff, however, the in situ calibration turned out to be difficult and lead to $R^{2}$ values only in the range of 0.13 to 0.56 . Nonetheless, Ferguson et al. (2002) found that there were consistent magnitudes and trends between calibrated sensor outputs and qualitative observations of moisture conditions and that the real-time sensor outputs were a great help for scheduling the experimental burns. A coaxial TDR sensor has been developed specifically for the measurement of forest floor litter by Canone et al. (2009). This "OZ" probe is a mixture of the coaxial (cylinder with a fully confined electrical field) and three-rod sensor designs and has been shown to measure volumetric water content in forest litter with an error range of $0.02 \mathrm{~m}^{3} \mathrm{~m}^{-3}$. Conedera et al. (2012) used soil moisture sensors of unknown type for duff and coniferous litter moisture measurements ("humus sentry", $R^{2}$ to manual volumetric samples 0.5 to 0.88 and 0.79 , respectively). Recently, Sheridan et al. (2014) used a high number of replications of low-cost soil moisture sensors installed in artificially constructed "litter packs" to investigate the spatial and temporal variability of fuel moisture in complex terrain in Victoria, Australia.

A commercial device for measuring fuel moisture by permittivity sensing is available in the "duff moisture meter" (Robichaud and Bilskie, 2004). To use this device, samples have to be obtained manually, passed through a sieve into a sample chamber, compressed using a torque-limiting knob and then measured using FD technique. While this procedure ensures more uniform packing and density of the fuels, manual sampling and device operation are required.

\subsubsection{Objectives}

This study aims to compare and evaluate four different sensor types, three based on permittivity and one on the method of electrical resistance sensing, in comparison to a large amount of gravimetrically determined moisture content data as reference. These electronic methods were chosen because they measure the fuel moisture content at the original fuel particles in the field without any destruction and because they can operate autonomously for a prolonged period. Type, strength and stability over time of the correlation between sensor and gravimetric moisture data are analyzed and compared to other studies in order to identify whether, and, if so, which, sensor is suitable for routine monitoring and thus hazards management.

\section{Methods}

\subsection{Research site}

The study site is located in the Kranzberg Forest $\left(48^{\circ} 24^{\prime} \mathrm{N}\right.$, $11^{\circ} 39^{\prime} \mathrm{E}$ ) close to Freising, Germany. It is part of a network of forest climate stations run by the Bavarian Forest Institute (Bayerische Landesanstalt für Wald und Forstwirtschaft - LWF). A map showing the location of the study site in

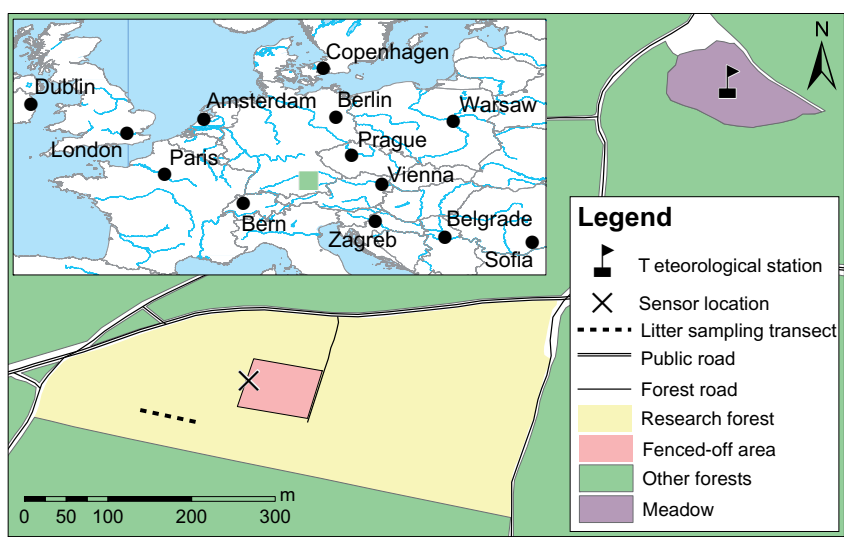

Figure 1. Map of the experimental site, including open-air meteorological station, research forest with fenced-off area, sensor location and litter sampling transect.

Europe, as well as the relative locations of the sensor position, sampling transect and the meteorological station, can be found in Fig. 1. The 7.1 ha site consists of a 160-year-old single-storied mature mixed forest stand made up of European beech (Fagus sylvatica L., 218 trees ha $^{-1}$ ) and pedunculate oak (Quercus robur L., 36 trees ha ${ }^{-1}$ ). The shrub and especially the moss layers are very scarce and patchy; thus the mull type humus layer is mostly found revealed. Its litter $\left(\mathrm{O}_{\mathrm{L}}\right)$ layer had an average height of $1.6 \mathrm{~cm}$ with a fuel load (oven dry) of $7.7 \mathrm{tha}^{-1}$ and a bulk density of $48 \mathrm{~kg} \mathrm{~m}^{-3}$ on 1 September 2010. Where ground vegetation is present, major species are small balsam (Impatiens parviflora DC.), touch-me-not balsam (Impatiens noli-tangere L.), European woodland sedge (Carex sylvatica Huds.) and European beech regeneration (cf. photograph in Fig. 2). The climate is subatlantic to subcontinental with an average annual temperature of $7.5^{\circ} \mathrm{C}$ and an average annual precipitation sum of $803 \mathrm{~mm}$, most of which occurs in summer (LWF, 1996).

\subsection{Meteorological measurements}

Meteorological data ( $2 \mathrm{~m}$ temperature, precipitation, $10 \mathrm{~m}$ wind speed and direction, radiation) were recorded throughout the study period at the open-air site of the forest climate station, which is approx. $400 \mathrm{~m}$ air-line distance from the study site (cf. Fig. 1). All parameters were gathered on a 15 min basis (mean, maximum or sum, where appropriate) and aggregated to the daily values presented here.

\subsection{Reference method}

More than $25 \mathrm{~m}$ from the edges of the forest stand, a $30 \mathrm{~m}$ long transect was established along which the sampling took place (cf. Fig. 1). This transect had the same sparse ground vegetation as the location of the sensors. Three samples were collected almost at the same time each day near the start, midpoint and end of the transect, between 11:00 and 
13:00 LST (local standard time). The exact sampling locations were chosen randomly every day; care was taken not to sample any litter that had been excessively trampled. Each sample was gathered by carefully removing the litter $\left(\mathrm{O}_{\mathrm{L}}\right)$ layer by hand and placing the material (e.g., dead leaves, small branches with a diameter $<4 \mathrm{~mm}$, dead parts of inflorescence or fruits) in a $500 \mathrm{~mL}$ polypropylene bottle until the bottle was loosely filled. Typical dry mass per sample was $13 \mathrm{~g}$. All bottles were closed, such that they were airtight, immediately after sampling to be weighed wet in the laboratory. Afterwards, they were opened, oven-dried at $105^{\circ} \mathrm{C}$ for $24 \mathrm{~h}$ and weighed again after a cool-down period of $30 \mathrm{~min}$ in desiccators. Along with the bottle tare weight determined previously, the gravimetric fuel moisture content of the individual samples (Eq. 1) and the daily mean of the three samples could be calculated. A precision balance (readability $0.01 \mathrm{~g}$ ) was used for the analyses.

\subsection{In situ measurements}

All in situ devices were placed inside the litter layer within the fenced-off area of the on-site forest climate station, about $25 \mathrm{~m}$ from the closer and about $50 \mathrm{~m}$ from the farther end of the manual sampling transect (cf. Fig. 1). The sensors were spread out in a randomized, rectangular grid over an area of approximately $2.0 \times 1.5 \mathrm{~m}^{2}$ and thus subjected to similar conditions than the transect. All sensors were placed in the middle of the height of the litter layer with a horizontal orientation and were not fixed in their positions. However, all cable ends were fixed to the nearby fence to avoid unintentional extraction of the sensors while reading out the data loggers and sensors from outside the fence. A sensor of each group is pictured in Fig. 3.

\subsubsection{Permittivity devices}

Three different types of permittivity sensors were used. The first sensor (sensor 1, group a) was a special FD sensor with a flat sensitive volume (approx. (height $\times$ breadth $\times$ length) $1 \times 7.5 \times 14 \mathrm{~cm}^{3}$; Ruth and Munch, 2005). Further eight non-commercial two-rod FD sensors (sensors 2-9, group b) with a sensitive volume of approximately $2 \times 3 \times 10.5 \mathrm{~cm}^{3}$ shared the same capacitance $(C,[\mathrm{pF}])$ calculation shown in Eq. (4). The input frequency values $(f,[\mathrm{kHz}])$ were recorded manually from a battery-powered, handheld display unit as data logging was not considered necessary for this initial study.

$C=\frac{584}{f-52.9}+8.45$.

Instrumental precision for this type of sensor is usually reported for calibrated soil moisture only (in this case: mean relative accuracy 0.14, according to Ruth and Munch, 2005). However, intrinsic instrument precision depends solely on the accuracy of frequency measurements, which is very high $\left(\sim 10^{-4}\right)$. Considering the material to be measured is highly porous and low-density forest litter, other measuring errors such as installation and contact to the litter itself can be expected to have a much higher influence on the overall error.

Furthermore, 12 commercial two-rod FD sensors (sensors 13-24, group d, $\mathrm{ECH}_{2} \mathrm{O}$ EC-5 by Decagon Devices) were used for a limited time period. They consisted of two rods cut out of each sensor's printed circuit board. Length and separation distance of the rods were $55 \mathrm{~mm}$ and $10 \mathrm{~mm}$, respectively. The sensor measurements were recorded automatically every $10 \mathrm{~min}$ with a battery-powered data logger and the values closest to each manual sampling time were chosen for analysis. All measurements were automatically converted into volumetric soil moisture $\theta$ using a standard (linear) calibration equation in the data logger (Campbell, 2004). The accuracy of this measurement was reported to be $\pm 3 \%$ in mineral soil; once more this error can be expected to increase markedly in forest litter.

\subsubsection{Electrical resistance sensing devices}

A low-cost wood-moisture meter and data logger, featuring three separate channels (sensors 10-12, group c, Scanntronic Materialfox mini, $20 \mathrm{k} \Omega-500 \mathrm{M} \Omega$, battery-powered, accuracy not given) was used for electrical resistance measurements. Individual leaves were used as the sensitive objects in this measuring method and connected by two alligator clips with a separation of approximately $1 \mathrm{~cm}$ each. Sampling interval and choice of values for analysis was identical to the commercial FD sensors. For this type of measurement it has to be considered that in addition to instrumental precision and installation, the available measuring range (corresponding roughly to $15-80 \%$ gravimetric moisture content in wood) may well be exceeded in forest fuels.

\subsection{Data availability}

Reference sampling was started on 22 March, the 81st day of the year (DOY), and completed on 31 October 2010 (DOY 304). During this time, gravimetric fuel moisture measurements were obtained for 215 days (96\%) as a reference.

The in situ sensors were operational for different time periods, depending on the sensor type. Details about this, as well as some basic statistics, can be found in Table 1. It should be noted, however, that the number of sensors per group that were operational may have changed from day to day, e.g., due to short-term equipment malfunction (dead batteries and wiring problems) and the long-term erratic behavior of electrical resistance (group b) sensor no. 12 from DOY 114 onwards.

\subsection{Data analysis}

For an overall assessment of meteorological and fuel moisture conditions during the sampling period, manually determined fuel moisture is plotted along with standard meteoro- 
Table 1. Data availability and basic statistics for the entire study period and the three periods defined in Sect. 3.2. Note that on a given day, not all sensors of each group may have been operational due to equipment malfunctions.

\begin{tabular}{|c|c|c|c|c|c|}
\hline & & Entire study period & Period 1 & Period 2 & Period 3 \\
\hline \multirow[t]{5}{*}{ Period } & Start date & 22 Mar 2010 & 29 Apr 2010 & 11 June 2010 & 28 June 2010 \\
\hline & Start DOY & 81 & 88 & 162 & 179 \\
\hline & End date & 31 Oct 2010 & 30 Apr 2010 & 13 Jun 2010 & 22 Jul 2010 \\
\hline & End DOY & 304 & 120 & 165 & 204 \\
\hline & Length (days) & 224 & 33 & 3 & 25 \\
\hline \multirow{4}{*}{$\begin{array}{l}\text { Gravimetric } \\
\text { litter } \\
\text { moisture } \\
(\%)\end{array}$} & Days & 215 & 30 & 3 & 25 \\
\hline & Mean & 168.6 & 60.7 & 67.3 & 58.3 \\
\hline & $\mathrm{SD}$ & 19.2 & 10.4 & 19.1 & 8.0 \\
\hline & Relative SD & 11.4 & 17.2 & 28.4 & 13.7 \\
\hline \multirow[t]{5}{*}{ Sensor group a } & Days & 186 & 30 & 3 & 23 \\
\hline & Avg. N per day & 1 & 1 & 1 & 1 \\
\hline & Mean & 151.2 & 27.0 & 49.7 & 61.1 \\
\hline & SD & - & - & - & - \\
\hline & Relative SD & - & - & - & - \\
\hline \multirow[t]{5}{*}{ Sensor group $b$} & Days & 184 & 30 & 3 & 23 \\
\hline & Avg. N per day & 7.9 & 8.0 & 8.0 & 8.0 \\
\hline & Mean & 164.7 & 42.0 & 84.5 & 86.7 \\
\hline & SD & 33.2 & 12.6 & 26.2 & 23.8 \\
\hline & Relative SD & 20.2 & 30.1 & 31.1 & 27.5 \\
\hline \multirow[t]{5}{*}{ Sensor group c } & Days & 205 & 29 & 3 & 25 \\
\hline & Avg. N per day & 2.5 & 3.0 & 3.0 & 3.0 \\
\hline & Mean & 259.8 & 55.8 & 139.6 & 111.6 \\
\hline & $\mathrm{SD}$ & 19.3 & 18.3 & 18.0 & 15.6 \\
\hline & Relative SD & 7.4 & 32.8 & 12.9 & 14.0 \\
\hline \multirow[t]{5}{*}{ Sensor group d } & Days & 47 & 29 & 0 & 0 \\
\hline & Avg. N per day & 12 & 12 & 0 & 0 \\
\hline & Mean & 139.0 & 53.5 & - & - \\
\hline & $\mathrm{SD}$ & 25.7 & 20.4 & - & - \\
\hline & Relative SD & 18.5 & 38.3 & - & - \\
\hline
\end{tabular}

logical parameters (daily maximum and mean temperature, daily cumulative precipitation).

In order to investigate the relationship of the individual sensor signals with manually determined litter moisture, each sensor's signal was rescaled linearly to the minimum and maximum of the manual measurements. For the flat-FD (group a), two-rod (group b) and $\mathrm{ECH}_{2} \mathrm{O}$ (group d) sensors, this was done directly using the $\mathrm{R}$ package "scale" function "rescale", as a linear correlation with manual measurements can be assumed irrespective of the physical value of the measurements. The resistance signal from sensor group $\mathrm{c}$ was inverted and log-transformed before rescaling to achieve a near-linear relationship with manual gravimetric measurements. It should be noted that not only was rescaling necessary to make the values from different sensor groups (i.e., different physical values) comparable but there was also a large sensor-to-sensor variation within each group due to the high variability of the litter layer (e.g., one sensor may have been installed in a rather shallow, low-density part of the lit- ter layer, whereas another of the same type might have been located in a high-density area; this produces highly different sensor outputs especially for the bulk-density-dependent FD sensors). As the rescaled values were only analyzed in reference to the litter moisture content and not to themselves (e.g., no correlation of one rescaled sensor to another rescaled sensor), we can exclude any interference of the rescaling process on our results, because correlations and linear regressions are invariant to linear transformations such as the rescaling used here. A similar approach was used by Conedera et al. (2012) for their soil moisture sensor-based "humus sentry", which is also highly affected by the bulk density in the immediate sensor vicinity.

For all sensor groups, Spearman correlations with the manually determined litter moisture were examined. In groups featuring more than one sensor $(b-d)$, the standard deviations of the daily values of all sensors of one group were investigated in relation to the respective daily sensor mean value, and sensor values with erratic standard devia- 


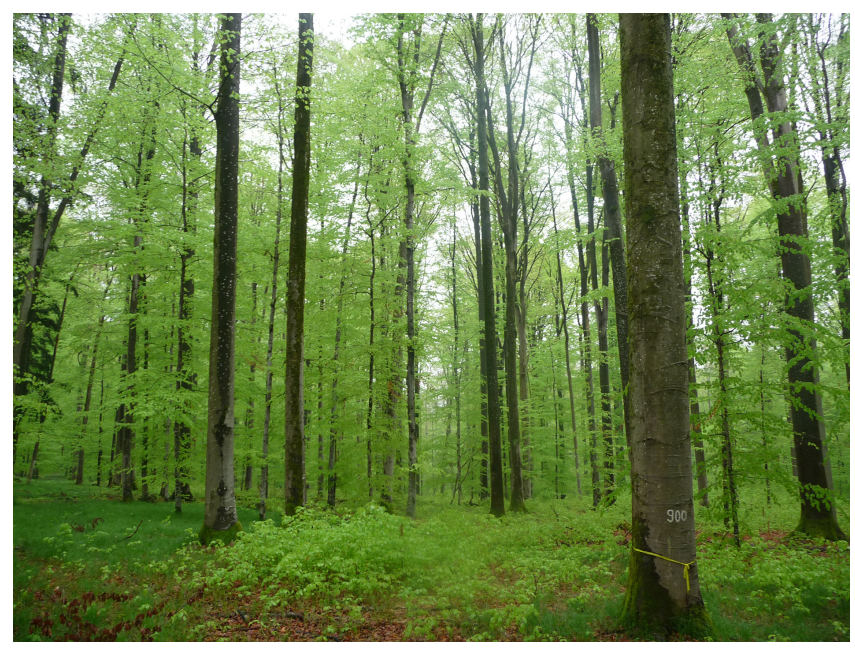

Figure 2. Photograph of the research forest, taken on 1 May 2010.

tions were identified. Sensor values as well as litter moisture and meteo-data for periods corresponding to erratic and nonerratic sensor standard deviations are shown and the coherence of the sensor-gravimetric moisture relationship investigated using linear regression and associated confidence intervals. Finally, the influence of the observations and analyses on the applicability of the different sensor types is discussed. All data analyses and plotting were performed in the statistical package R, version 3.1.1 (R Core Team, 2014), and its packages RODBC, doBy, scales and Metrics.

\section{Results}

\subsection{Gravimetrically determined fuel moisture and weather conditions}

Results of the gravimetric reference measurements, daily cumulative precipitation as well as mean and maximum temperatures are summarized in Fig. 4. During most of the study period, unusually frequent and heavy precipitation events kept fuel moisture high and fire danger low. However, two major dry periods occurred in April (DOY 90 onwards) and July (DOY 165 onwards) 2010. Minimum, median and maximum daily fuel moisture throughout the study period were 13, 175 and $395 \%$, respectively. The relative standard deviation within the daily gravimetric measurements of 1.1 to $66.9 \%$ was rather high (data not shown here). However, it tended to decrease with decreasing fuel moisture.

\subsection{Sensor data and correlation to gravimetric fuel moisture}

Figure 5 shows scatterplots as well as Spearman's rank correlation coefficients for the mean rescaled sensor value, manually determined litter moisture and the different sensor groups. While the permittivity-based sensor groups a, b and
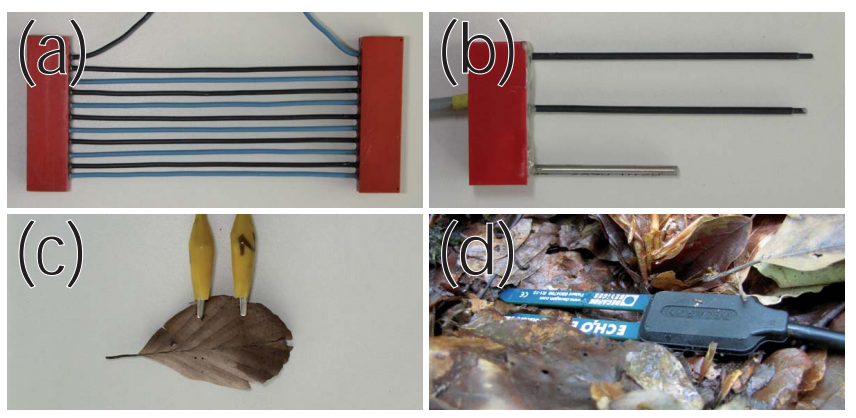

Figure 3. Photographs of the sensors used: (a) flat volume permittivity sensor (group a), (b) non-commercial two-rod permittivity sensor (group b), (c) electrical resistance sensor (group c) and (d) commercial $\mathrm{ECH}_{2} \mathrm{O}$ two-rod permittivity sensor (group d).

d show relatively obvious linear correlations, the resistance sensors (group c) exhibit a non-linear and almost logistic relationship with many high and low values and a sharp transition in-between. As there was only one sensor in group a (flat permittivity sensor), all of its values are marked as $n<3$ (gray). The same is true for all resistance (group c) readings taken after DOY 114 when one of three sensors developed a fatal error.

Spearman's rank correlation coefficients showed highly significant $(p<0.001)$ correlations for all four sensor groups with higher correlations for permittivity (group a, 0.837; group b, 0.891; group d, 0.947) than for electrical resistance (group c, 0.792) sensors. The highest rank correlation coefficient was observed for group d $\left(\mathrm{ECH}_{2} \mathrm{O}\right.$ commercial two-rod sensors, 0.947), which were only used for a very limited time period, however.

Considering the dependence of standard deviation on sensor mean values shown in Fig. 6, all sensors of groups b-d exhibited an increase that is nearly linear to the sensor mean value at first, while showing some irregular patterns and scatter at higher sensor mean values. For the resistance sensors (group c), a marked decrease of standard deviation could be observed at very high mean values (>300).

Those ranges of sensor mean values, where sensor standard deviation was behaving irregularly and showing a high scatter, have to be considered as potentially unsuitable for reliable measurements. Therefore, a threshold sensor value of 100 for the permittivity sensors (groups b and d) and 50 for group c (electrical resistance sensors) was defined visually and shown in Fig. 6 as vertical dashed lines.

Figure 4 (lower three panels) shows the evolution of litter moisture content and the rescaled sensor mean values with the colors indicating values above and below the respective thresholds. Naturally, the values below the thresholds are almost exclusively limited to the dry periods mentioned above, with the exception of a very short dry period at the end of June. Based on the sensor data and standard deviation classification, these periods were defined and labeled as periods 


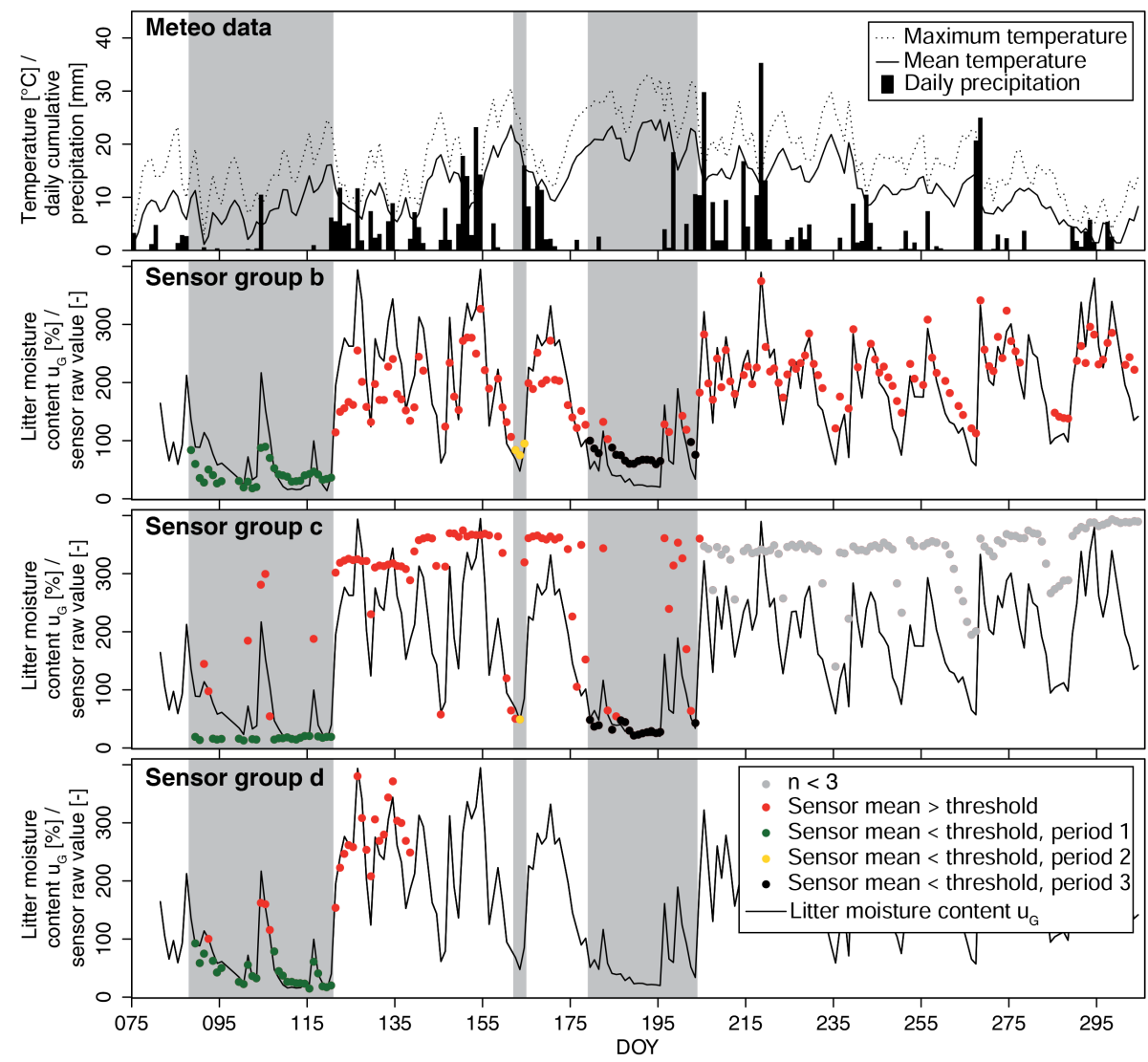

Figure 4. Meteorological data and litter moisture content $\left(u_{\mathrm{G}}\right)$, as well as rescaled sensor mean values during the study period. Colored dots indicate sensor mean values: calculated from less than three sensors (gray), beyond the threshold set in Fig. 6 (red), below the threshold and part of period 1 (green), below the threshold and part of period 2 (yellow) and below the threshold and part of period 3 (black). The gray areas correspond to periods 1-3 defined in Sect. 3.2.

1, 2 and 3 (indicated by green, yellow and black dots in Fig. 4, respectively). For data concerning the exact start and end dates of these periods, as well as some basic statistics, consult Table 1.

For the two longer-lasting dry periods (periods 1 and 3), linear regressions and associated confidence intervals were calculated for each individual sensor of group $b$ and $c$ and shown in Fig. 7 along with the data points of the short dry interval in June (period 2). The associated regression parameters can be obtained from Table 2 .

It can be observed that for most combinations, linear regression was well suited to describe the relationship of the rescaled sensor values and the gravimetrically measured litter moisture content. However, there were large differences of those relationships determined in periods 1 and 3, with values from period 2 generally falling between and/or slightly closer to those of period 3. The confidence intervals (dashed lines) of the respective regressions only overlapped at the extreme dry range of litter moisture and sensor values, thus indicating that the underlying relationships were actually significantly different. Additionally, only few measurements of one period could be found within the confidence intervals of the regression based on the other period. For the two-rod sensors (group b, 2-9), the regression slope tended to decrease and the intercept tended to increase from period 1 to period 3 . Even the few values of period 2 fell between the two regressions and thus support this shift in the regression line. Additionally, coefficients of determination tended to increase and confidence intervals to narrow from period 1 to period 3 . The electrical resistance sensors (10-12, group c) showed an even more extreme behavior: while there were very poorfitting $\left(R^{2}<0.05, p>0.1\right)$ negative regression lines in period 1 , regression in period 3 worked better $\left(R^{2}>0.32, p<0.05\right)$, producing a positive slope.

\section{Discussion}

Due to the unusually frequent and intense precipitation (for the study area) during the test period in 2010 (cf. Fig. 4), conditions were generally not favorable to forest fire occurrence and greatly complicated a test of litter moisture measuring techniques. Only a very limited number of dry periods occurred during which (gravimetric) litter moisture dropped 

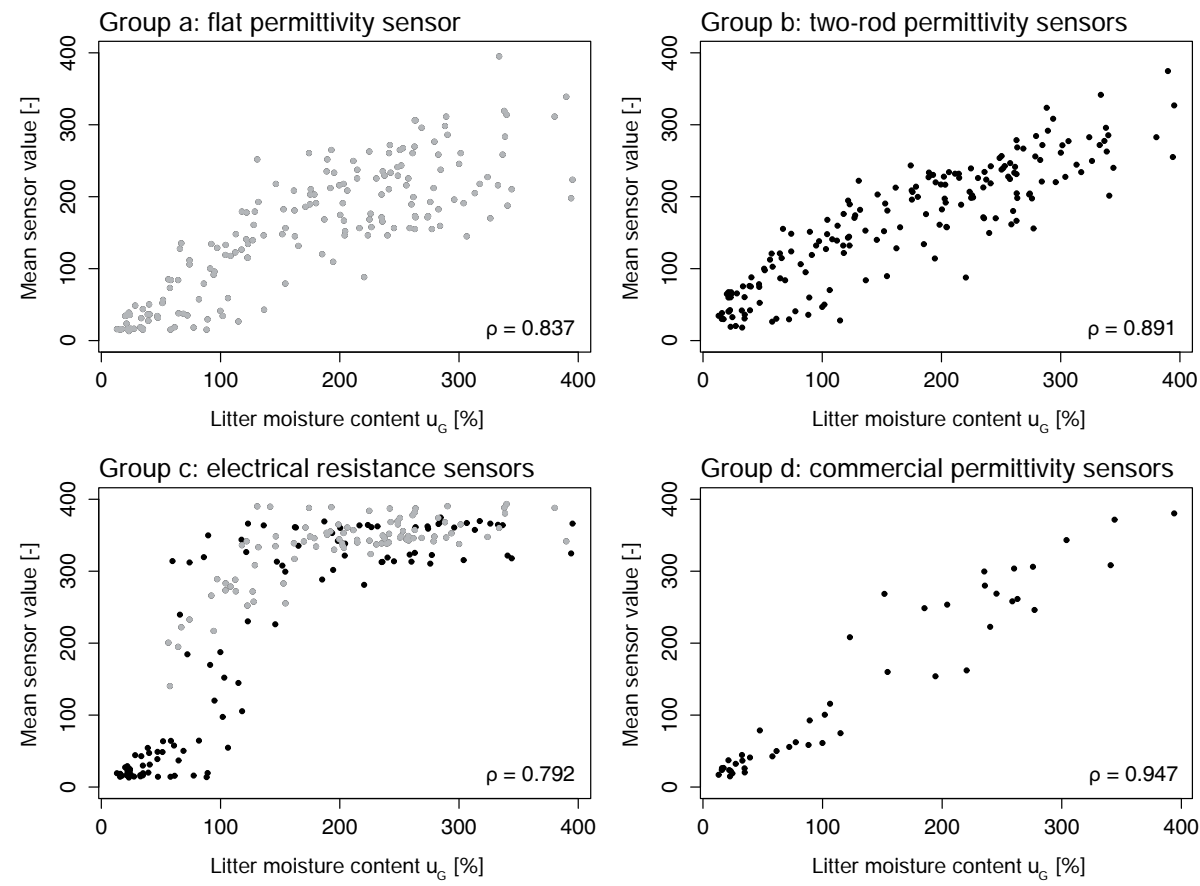

Figure 5. Mean rescaled sensor values vs. manually determined litter moisture content $u_{\mathrm{G}}$ for all data available. Gray dots indicate means that were calculated from less than three observations; Spearman's correlation coefficients $(\rho)$ are based on all available data (black and gray dots). All correlations are highly statistically significant $(p<0.001)$.
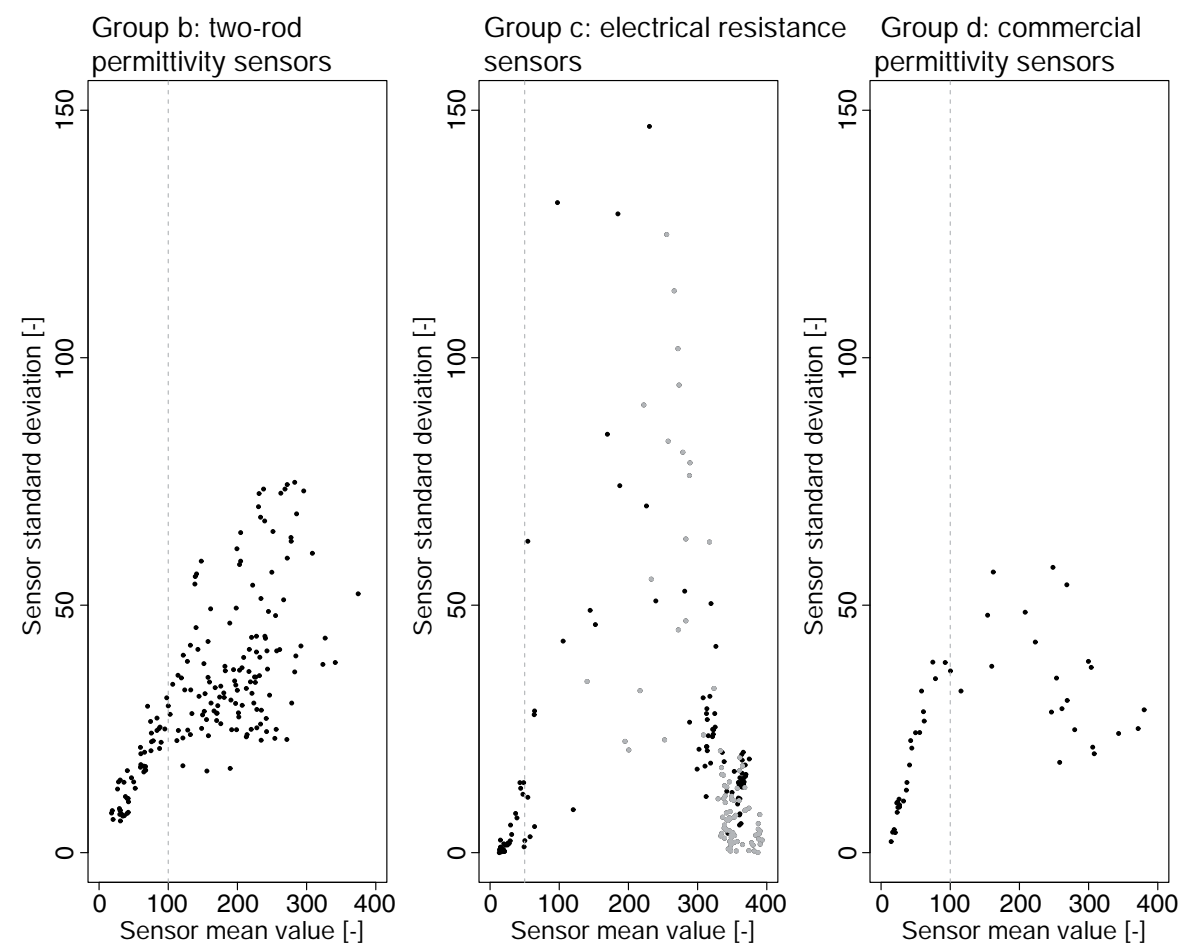

Figure 6. Standard deviation of the different sensor groups as a function of sensor mean value. Gray dots indicate standard deviations and means that were calculated from two observations only. The dashed gray line represents the threshold sensor mean value that was determined visually to limit the values to a range where sensor mean value and sensor standard deviation were more correlated. Group a was left out as it consists of one sensor only. 

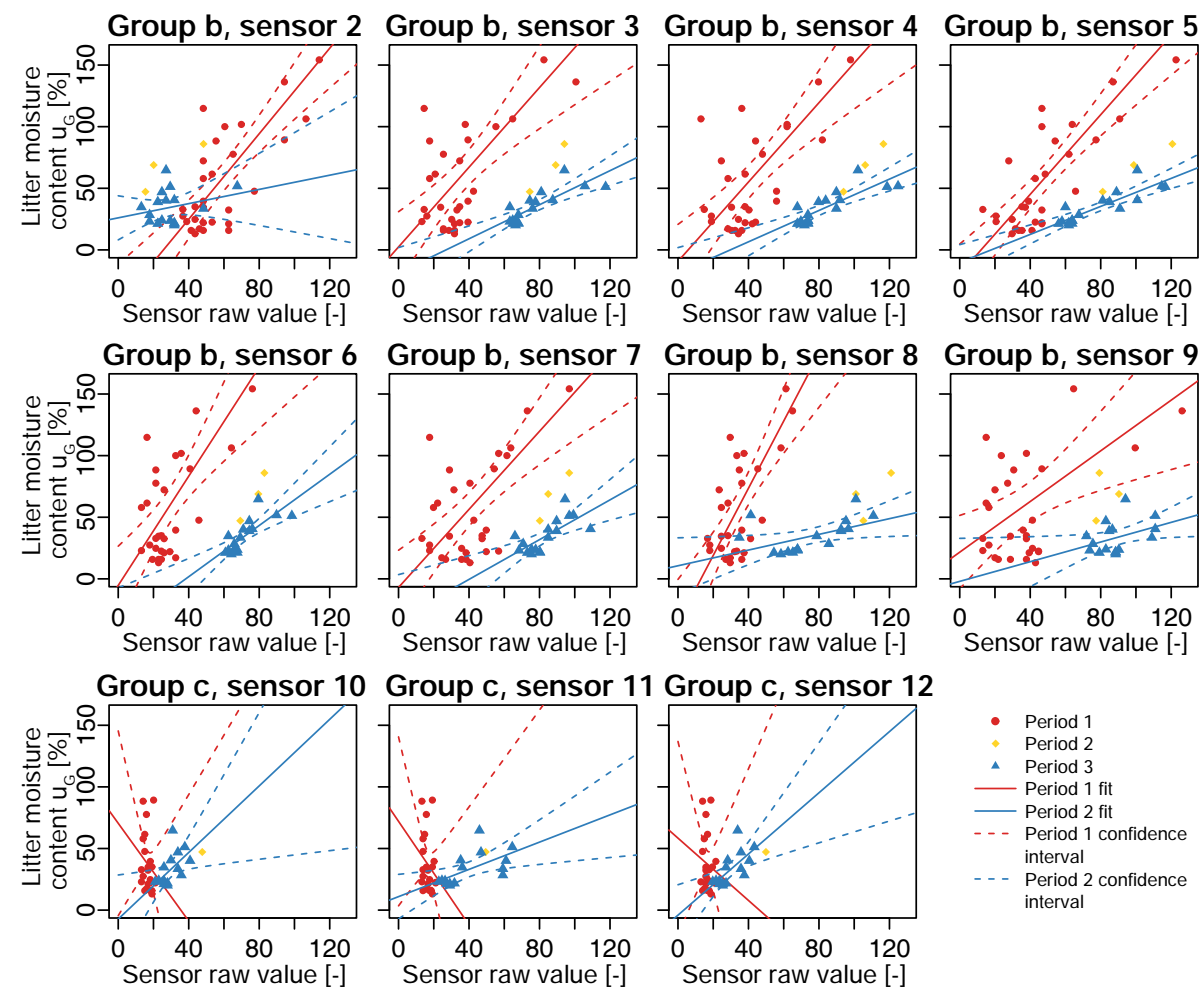

Figure 7. Linear regressions and associated confidence intervals calculated for periods 1 and 3 for each individual sensor of groups b and c, respectively. Yellow diamonds: sensor and litter moisture values during period 2. Group b: two-rod permittivity sensors, sensors 2-9; group c: sensors 10-12, electrical resistance. For basic statistics regarding the periods and regression parameters, cf. Tables 1 and 2 , respectively.

to levels low enough to be meaningful for fire danger and behavior applications (i.e., in the range of $30 \%$ and lower; Wright, 1967). Interestingly, it can be observed that even data from the gravimetric reference technique are characterized by high variability (relative standard deviation up to $66.9 \%$ ) at high litter moisture (data not shown). A similar pattern was observed by Ferguson et al. (2002). Part of the variation in the gravimetric measurements certainly was due to spatial variation of fuel moisture on the ground (i.e., some sampling locations being more sheltered by the canopy whereas others are more open) and sampling inconsistencies (e.g., sampling depth linked to areas with a deeper or shallower litter layer and a steep vertical gradient of moisture within the litter when wetting or drying occurred).

When the sensor raw values were rescaled and the averages of each sensor group compared to concurrent gravimetric litter moisture measurements (cf. Fig. 5), linear relationships could be visually identified for all permittivity sensors (groups $\mathrm{a}, \mathrm{b}$ and $\mathrm{d}$ ). The very poor, non-linear relationships for the electric resistance technique (group c) could be due to an exceedance of the sensor range both in the maximum and minimum or to a suboptimal transformation of the raw values. The latter may especially be due to the fact that it was necessary to invert and log-transform the resistance signal before rescaling in order to achieve a near-linear relationship (cf. Sect. 2.6) and that other, more complicated and partially confidential transformations, are used by the wood moisture sensor industry (cf. Sect. 1.2.3 and Eq. 2). As the device used was a wood moisture analyzer normally working in a range of 15 to $80 \%$ gravimetric moisture content, it was fairly clear that despite the different measuring setup, at least the upper end of the range was exceeded.

Overall, the correlation of automatic vs. manual gravimetric measurements seemed somewhat more robust than in Ferguson et al. (2002) (Spearman's rank correlation 0.792 to 0.947 compared to second-degree polynomial calibration $R^{2}$ of 0.129 to 0.558 ) and was very similar to the mean results of three "humus sentries" placed in conifer needles by Conedera et al. (2012), $R^{2} 0.79$. Borken et al. (2003) gave a calibration $R^{2}$ of 0.72 and 0.68 for the mean of their $12 \mathrm{Oi}$ and $24 \mathrm{Oe} /$ Oa horizon electrical resistance sensors, respectively. As they used the half-bridge voltage as the independent variable, no log-transformation of their resistance measurements was necessary and linear regressions could be carried out directly. The different strengths of correlation/regression may be due to a number of factors, including the sensor type and placement, litter type, fuel moisture range during the study period, number of reference measurements made, averaging effects for Borken et al. (2003) and Conedera et al. (2012) and the use of volumetric (Conedera et al., 2012) and log- 
Table 2. Regression parameters for the linear relationships shown in Fig. 7.

\begin{tabular}{|c|c|c|c|c|c|c|c|}
\hline Group & Sensor & Period & $R^{2}$ & $p$ value & $\mathrm{N}$ & Intercept & Slope \\
\hline $\mathrm{b}$ & 2 & 1 & 0.64 & $<0.0001$ & 30 & -44.49 & 1.73 \\
\hline $\mathrm{b}$ & 2 & 3 & 0.07 & $<0.5$ & 17 & 26.01 & 0.29 \\
\hline $\mathrm{b}$ & 3 & 1 & 0.45 & $<0.0001$ & 30 & 2.43 & 1.62 \\
\hline $\mathrm{b}$ & 3 & 3 & 0.68 & $<0.0001$ & 17 & -18.63 & 0.69 \\
\hline $\mathrm{b}$ & 4 & 1 & 0.50 & $<0.0001$ & 30 & -9.29 & 1.61 \\
\hline $\mathrm{b}$ & 4 & 3 & 0.68 & $<0.0001$ & 17 & -18.88 & 0.64 \\
\hline $\mathrm{b}$ & 5 & 1 & 0.67 & $<0.0001$ & 30 & -19.55 & 1.62 \\
\hline $\mathrm{b}$ & 5 & 3 & 0.76 & $<0.0001$ & 17 & -10.17 & 0.57 \\
\hline $\mathrm{b}$ & 6 & 1 & 0.45 & $<0.0001$ & 30 & -5.31 & 2.22 \\
\hline $\mathrm{b}$ & 6 & 3 & 0.62 & $<0.0005$ & 17 & -39.81 & 1.04 \\
\hline $\mathrm{b}$ & 7 & 1 & 0.49 & $<0.0001$ & 30 & -6.95 & 1.58 \\
\hline $\mathrm{b}$ & 7 & 3 & 0.52 & $<0.005$ & 17 & -32.71 & 0.81 \\
\hline $\mathrm{b}$ & 8 & 1 & 0.56 & $<0.0001$ & 30 & -35.55 & 2.73 \\
\hline $\mathrm{b}$ & 8 & 3 & 0.27 & $<0.05$ & 17 & 10.63 & 0.32 \\
\hline $\mathrm{b}$ & 9 & 1 & 0.27 & $<0.005$ & 30 & 21.65 & 1.03 \\
\hline $\mathrm{b}$ & 9 & 3 & 0.26 & $<0.05$ & 17 & -2.05 & 0.40 \\
\hline $\mathrm{c}$ & 10 & 1 & 0.04 & $<0.5$ & 22 & 70.45 & -1.98 \\
\hline $\mathrm{c}$ & 10 & 3 & 0.32 & $<0.05$ & 15 & -7.26 & 1.35 \\
\hline $\mathrm{c}$ & 11 & 1 & 0.05 & $<0.5$ & 22 & 72.03 & -2.10 \\
\hline $\mathrm{c}$ & 11 & 3 & 0.38 & $<0.05$ & 15 & 10.95 & 0.55 \\
\hline $\mathrm{c}$ & 12 & 1 & 0.02 & $>0.5$ & 22 & 58.42 & -1.26 \\
\hline $\mathrm{c}$ & 12 & 3 & 0.46 & $<0.01$ & 15 & -4.09 & 1.24 \\
\hline $\mathrm{d}$ & 13 & 1 & 0.72 & $<0.0001$ & 25 & 0.81 & 1.25 \\
\hline $\mathrm{d}$ & 13 & 3 & - & - & - & - & 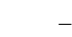 \\
\hline $\mathrm{d}$ & 14 & 1 & 0.59 & $<0.0001$ & 25 & -10.75 & 0.91 \\
\hline d & 14 & 3 & - & - & - & - & - \\
\hline $\mathrm{d}$ & 15 & 1 & 0.34 & $<0.005$ & 25 & 18.66 & 0.58 \\
\hline d & 15 & 3 & - & - & - & - & - \\
\hline $\mathrm{d}$ & 16 & 1 & 0.74 & $<0.0001$ & 25 & 13.12 & 0.57 \\
\hline d & 16 & 3 & - & - & - & - & - \\
\hline d & 17 & 1 & 0.10 & $<0.5$ & 25 & 29.15 & 0.62 \\
\hline d & 17 & 3 & - & - & - & - & - \\
\hline d & 18 & 1 & 0.65 & $<0.0001$ & 25 & -4.19 & 1.61 \\
\hline $\mathrm{d}$ & 18 & 3 & - & - & - & - & - \\
\hline $\mathrm{d}$ & 19 & 1 & 0.51 & $<0.0001$ & 25 & 11.54 & 0.64 \\
\hline $\mathrm{d}$ & 19 & 3 & - & - & - & - & - \\
\hline $\mathrm{d}$ & 20 & 1 & 0.05 & $<0.5$ & 25 & 33.46 & 0.37 \\
\hline $\mathrm{d}$ & 20 & 3 & - & - & - & - & - \\
\hline $\mathrm{d}$ & 21 & 1 & 0.65 & $<0.0001$ & 25 & 1.58 & 1.59 \\
\hline d & 21 & 3 & - & - & - & - & - \\
\hline d & 22 & 1 & 0.75 & $<0.0001$ & 25 & 6.41 & 0.94 \\
\hline d & 22 & 3 & - & - & - & - & - \\
\hline d & 23 & 1 & 0.35 & $<0.005$ & 25 & 15.97 & 0.69 \\
\hline d & 23 & 3 & - & - & - & - & - \\
\hline $\mathrm{d}$ & 24 & 1 & 0.65 & $<0.0001$ & 25 & 3.88 & 0.78 \\
\hline d & 24 & 3 & - & - & - & - & - \\
\hline
\end{tabular}

scaled volumetric reference measurements in Ferguson et al. (2002).

The standard deviations across the range of sensor mean values for sensor types b, c and d (Fig. 6) suggest that there is a transition from an almost linear increase of standard deviation to an irregular pattern above a sensor value of 100 (sensor type b and d) and 50 (sensor type c), respectively. This transition may be due to proximity to the end of the measuring range, high spatial variability of litter moisture at high moisture contents (as suggested by increased gravimetric standard deviations) or even a redistribution of litter elements within the sensitive volumes due to heavy precipitation. For the electric resistance sensors (group c) it can be observed that as the measuring range is exceeded (mean sensor value > 280), standard deviations decrease again. Fortunately, this irregular pattern of standard deviation as compared to sensor mean value occurs at the high end of the measuring scale, where fire danger is practically non-existent in any case (gravimetric litter moisture usually beyond $100 \%$ ). Therefore, periods where the sensors had to be considered unreliable can be labeled as not representing fire danger. When trying to compare the standard deviations encountered to the instrumental precision reported in Sect. 2.4, it turns out that this is not readily possible, as different scales and measures are being used. It should be noted, however, that the absolute and relative standard deviations (e.g., reported in Table 1) are quite high. They may be one or several orders of magnitude higher than what has been reported for the instruments themselves, which is probably due to the placement of relatively precise sensors in a very heterogeneous and variable litter bed.

Introduction of thresholds for maximum reasonable sensor values lead to a limitation to few dry periods, as visible in Fig. 4. When linear regressions were carried out and compared in those periods (Fig. 7, Table 2), significant differences between periods 1 and 3 could be found, whereas the values of the very short period 2 lay in-between. For group b (two-rod permittivity sensors), slopes of regression tended to decrease from period 1 to period 3. Considering Eq. (3), an increasing sensor raw value (over time) for similar litter moisture content, and thus lower slopes of regression, suggests that an increase of the litter bulk density $\left(\rho_{\mathrm{m}}\right)$ had occurred in the meantime. Due to settling, decomposition of the litter layer and installation of the sensors only a few days before the start of period 1 , this was a process that certainly occurred in the litter layer while the measurements were carried out. Further corroboration for this was observed when the sensors were uninstalled and found in a dense mat of semidecomposed litter. Higher bulk density around the sensors would also explain part of the increased sensor performance in period 3 (generally higher coefficients of determination and thus higher sensitivity). A similar behavior can also be expected for groups a and d (flat volume and commercial FD sensors, respectively); however, this could not be shown as group a consisted of only one sensor (thus the standard deviation threshold analysis could not be carried out) and the group d sensors were only in use for a limited time period not containing dry periods 2 and 3 . The changes over time in litter properties and thus in the calibration equations necessary to convert the sensor raw values into measures of litter moisture present a severe limitation in the use of these sensors in the field, as frequent recalibrations would have to be carried out. Very poor regressions for the electrical resistance sensors (group c) during period 1, as opposed to period 3, suggest that the sensors were still showing influences of the recent installation and that the values gathered during period 1 are not reliable. As the measurement is not directly influenced by bulk density, however, this is probably not related to the same processes identified for sensor group $b$. The overall 
bad performance of the electrical resistance technique indicates that extensive additional fine-tuning and testing is required if this technique is to be used for litter moisture monitoring.

\section{Conclusions}

Despite relatively wet weather conditions and generally low fire danger, different sensors for the determination of litter moisture could be tested and valuable insights gained. All sensors showed erratic behavior at very high litter moisture contents; however, they are not relevant for forest fire applications as these conditions are not linked to fire danger and may not even occur in more fire-prone regions. While significant correlations and regressions between the rescaled sensor raw values and gravimetrically determined litter moisture could be obtained for all sensors tested, significant differences between the regressions for periods 1 and 3 (in March/April and June/July, respectively) suggest that changes over time within the litter layer affect the sensor's raw value-litter moisture relationship. Thus, sensors should not be calibrated only once in situ directly after installation. In contrast, relatively frequent recalibration (e.g., at least every 2 or 3 months) is necessary. Additionally, more work on the precise fine-tuning of the very poor performing resistance sensors would have to be done if this measuring technique were to be used. However, their generally limited measuring range should be considered.

Consequently, all of the tested methods may seem to be too complex for routine monitoring applications, e.g., for operational fire risk management and prevention, where an easyto-use and reliable technique is desirable. However, they may still be interesting for scientific studies, especially when manual gravimetric fuel moisture determination, which can be used for the necessary calibration, is to be carried out anyway. Placing the sensors described here in an artificially constructed fuel bed that is kept together by, e.g., a wire frame (cf. "litter packs" in Sheridan et al., 2014) or the use of other reference materials may reduce some of the difficulties found in this study and eventually lead to a better hazards management applicability.

Acknowledgements. The authors would like to thank all colleagues, student assistants and friends who have helped with the manual sampling campaign and the Bavarian State Forest Research Institute (LWF) for the use of their research forest and supply of meteorological data. Financial support is acknowledged from the Bavarian State Ministry for Nutrition, Agriculture and Forestry through project KLIP 8 and from the European Union through the Alpine Space ALP FFIRS project (no. 15-2-3-IT) as well as from the European Research Council under the European Union's Seventh Framework Programme (FP7/2007-2013)/ERC grant agreement no. 282250. The authors furthermore gratefully acknowledge the support by the Faculty Graduate Center Weihenstephan of TUM Graduate School at Technische Universität München, Germany.
This work was supported by the German Research Foundation (DFG) and the Technische Universität München within the funding programme Open Access Publishing.

Edited by: P. Tarolli

Reviewed by: S. Ferraris and one anonymous referee

\section{References}

Aguado, I., Chuvieco, E., Boren, R., and Nieto, H.: Estimation of dead fuel moisture content from meteorological data in Mediterranean areas, Applications in fire danger assessment, Int. J. Wildland Fire, 16, 390-397, doi:10.1071/WF06136, 2007.

Beall, H. W.: The duff hygrometer as an aid to fire weather research, Forest. Chron., 4, 20-22, doi:10.5558/tfc4020-3, 1928.

Beck, J. A. and Armitage, O. B.: Diurnal fine fuel moisture and FFMC characteristics at northern latitudes, in: Proceedings of the 22nd Tall Timbers Fire Ecology Conference: Fire in Temperate, Boreal, and Montane Ecosystems, Tallahassee, FL, 211-221, 2001.

Blonquist Jr., J. M., Jones, S. B., and Robinson, E. A.: A time domain transmission sensor with TDR performance characteristics, J. Hydrol. 314, 235-245, doi:10.1016/j.jhydrol.2005.04.005, 2005.

Borken, W., Davidson, E. A., Savage, K., Gaudinski, J., and Trumbore, S. E.: Drying and wetting effects on carbon dioxide release from organic horizons, Soil Sci. Soc. Am. J., 67, 1888-1896, doi:10.2136/sssaj2003.1888, 2003.

Campbell, C. S.: Calibrating $\mathrm{ECH}_{2} \mathrm{O}$ soil moisture probes, Decagon Application Note, Decagon Devices, Inc., Pullman, Washington, 4 pp., 2004.

Campbell, J. E.: Dielectric properties and influence of conductivity in soils at one to 50 megehertz, Soil, 54, 332-341, doi:10.2136/sssaj1990.03615995005400020006x, 1990.

Canone, D., Previati, M., Ferraris, S., and Haverkamp, R.: A new coaxial time domain reflectometry probe for water content measurement in forest floor litter, Vadose Zone J., 8, 363-372, doi:10.2136/vzj2008.0110, 2009.

Chandler, C., Cheney, P., Thomas, P., Trabaud, L., and Williams, D.: Fire in forestry - forest fire behaviour and effects, John Wiley $\&$ Sons, New York, Chinchester, Brisbane, Toronto, Singapore, 450 pp., 1983.

Chatto, K. and Tolhurst, K.: Development and testing of the Wiltronics T-H Fine Fuel Moisture Meter, Department of Natural Resources and Environment, Fire Management Branch, CFFT Creswick Research Station, Research Report No. 46, East Melbourne, Australia, 1997.

Conedera, M., Brini, M., Calabrese, R., Ascoli, D., and Pezzatti, G. B.: Verifica sperimentale del Sistema FireLess2, Sherwood, 18, 25-31, 2012.

Ferguson, S. A., Ruthford, J. E., McKay, S. J., Wright, D., Wright, C., and Ottmar, R.: Measuring moisture dynamics to predict fire severity in longleaf pine forests, Int. J. Wildland Fire, 11, 267279, doi:10.1071/WF02010, 2002.

Forest Products Laboratory: Wood handbook - Wood as an engineering material, USDA Forest Service, Forest Products Labo- 
ratory, General Technical Report FPL-GTR-113, Madison, Wisconsin, 1999.

Gisborne, H. T.: The wood cylinder method of measuring forest inflammability, J. Forest., 31, 673-679, 1933.

Gonçalves, D. P., Pedrosa, L. S., Lopes, S. M. G., Viegas, D. X., and de Lemos, L. T.: The relation between the moisture content of fine forest fuels and several forest fire related aspects, in: Proceedings of the V International Conference on Forest Fire Research, Coimbra, Portugal, CD-ROM, Elsevier, Amsterdam, 2006.

Haines, D. A. and Frost, J. S.: Weathering effects on fuel moisture sticks: corrections and recommendations, USDA Forest Service, North Central Forest Experiment Station, Research Paper NC154, St. Paul, Minnesota, 1978.

Hardy, C. C. and Hardy, C. E.: Fire danger rating in the United States of America: an evolution since 1916, Int. J. Wildl. Fire, 16, 217-231, doi:10.1071/WF06076, 2007.

Keylwerth, R. and Noack, D.: Über den Einfluß höherer Temperaturen auf die elektrische Holzfeuchtigkeitsmessung nach dem Widerstandsprinzip, Holz Roh. Werkst., 14, 162-172, doi:10.1007/BF02617621, 1956.

Lin, C. P.: Frequency domain versus travel time analyses of TDR waveforms for soil moisture measurements, Soil Sci. Soc. Am. J., 67, 720-729, 2003.

Lopes, S. M. G., Viegas, D. X., Viegas, M. T., and de Lemos, L. T.: Moisture content of fine forest fuels in the Central Portugal (Lousa) for the Period 1996-2004, Forest Ecol. Manag. 234, S71, doi:10.1016/j.foreco.2006.08.103, 2006.

LWF: Bayerische Waldklimastationen: Jahrbuch 1996, Bayerische Landesanstalt für Wald und Forstwirtschaft, Freising, Germany, 1996.

Matthews, S.: Effect of drying temperature on fuel moisture content measurements, Int. J. Wildland Fire, 19, 800, doi:10.1071/WF08188, 2010.

Nadler, A. and Lapid, Y.: An improved capacitance sensor for in situ monitoring of soil moisture, Aus. J. Soil Res., 34, 361-368, doi:10.1071/SR9960361, 1996.

Pyne, S. K., Andrews, P. L., and Laven, R. D.: Introduction to Wildland Fire, John Wiley \& Sons, New York, Chichester, Brisbane, Toronto, Singapore, 1996.

R Core Team: R: A language and environment for statistical computing, R Foundation for Statistical Computing, Vienna, Austria, http://www.R-project.org/ (last access: 4 February 2016), 2014.

Robichaud, P. R. and Bilskie, J.: A new tool for fire managers an electronic duff moisture meter, Fire Management Today, 64, 15-18, 2004.

Robinson, M. and Dean, T. J.: Measurement of near surface soil water content using a capacitance probe, Hydrol. Process., 7, 7786, doi:10.1002/hyp.3360070108, 1993.
Ruth, B. and Munch, J. C.: Field measurements of the water content in the top soil using a new capacitance sensor with a flat sensitive volume, J. Plant Nutr. Soil Sc., 168, 169-175, doi:10.1002/jpln.200421624, 2005.

Ruthford, J. E. and Ferguson, S. A.: Measuring moisture dynamics to predict fire severity in longleaf pine forests, in: Proceedings of the fourth Symposium on Fire and Forest Meteorology, Reno, Nevada, 8 pp., 2001.

Schröder, P.: Die Verwendung der Streufeuchtigkeit zur Waldbrandprognose in Kieferngebieten, thesis, Technische Universität Dresden, Dresden, Germany, 1968.

Seyfried, M. S. and Murdock, M. D.: Measurement of soil water content with a 50-MHz soil dielectric sensor, Soil Sci. Soc. Am. J., 68, 394-403, doi:10.2136/sssaj2004.3940, 2004.

Sheridan, G., Nyman, P., Metzen, D., and Lane, P.: High resolution spatial and temporal variability of fine dead fuel moisture content in complex terrain, in: Advances in forest fire research, Imprensa da Universidade de Coimbra, Coimbra, Portugal, 303 306, doi:10.14195/978-989-26-0884-6_32, 2014.

Thomas, A. M.: In situ measurement of moisture in soil and similar substances by fringe capacitance, J. Sci. Instrum., 43, 21-27, doi:10.1088/0950-7671/43/1/306, 1966.

Topp, G. C., Davis, J. L., and Annan, A. P.: Electromagnetic determination of soil water content using TDR: Applications to wetting fronts and steep gradients, Soil Sci. Soc. Am. J., 46, 672678, doi:10.2136/sssaj1982.03615995004600040002x, 1982.

v. Wilpert, K., Nell, U., Lukes, M., and Schack-Kirchner, H.: Precision of soil moisture measurements done with "Time Domain Reflectometry" and "Frequency Domain Probes" in heterogeneous forest soils, Z. Pflanz. Bodenkunde, 161, 179-185, doi:10.1002/jpln.1998.3581610214, 1998.

Vogel, K., Wegener, G., Tröger, F., Geissler, A., Zimmer, B., Rösler, M., Nebel, B., Hauser, G., and Kaiser, A.: Einbau von unbehandelten Holzspänen in einem Keck GmbHMusterhaus und begleitende messtechnische Untersuchungen, Holzforschung München, final report DBU, Munich, Germany, 2002.

Wittich, K.-P.: A single-layer litter-moisture model for estimating forest-fire danger, Meteorol. Z., 14, 157-164, doi:10.1127/09412948/2005/0017, 2005.

Wotton, B. M., Stocks, B. J., and Martell, D. L.: An index for tracking sheltered forest floor moisture with the Canadian Forest Fire Weather Index System, Int. J. Wildland Fire, 14, 169-182, doi:10.1071/WF04038, 2005.

Wright, J. G.: Forest-fire hazard research as developed and conducted at the Petawawa Forest Experiment Station, Canadian Forest Service, Department of Forestry and Rural Development, Forest Fire Research Institute, Information Report FF-X-5, Ottawa, Ontario, Canada, a reprint of the 1932 edition, 1967. 